\title{
Screening of cultivars for tissue culture response and establishment of genetic transformation in a high-yielding and disease-resistant cultivar of Theobroma cacao
}

\author{
Jesse Jones ${ }^{1}$ - Elaine Zhang ${ }^{1} \cdot$ Dominick Tucker $^{1} \cdot$ Daniel Rietz $^{1} \cdot$ Douglas Dahlbeck $^{2} \cdot$ Michael Gomez $^{1}$. \\ Claudia Garcia ${ }^{3}$. Jean-Philippe Marelli ${ }^{4} \cdot{\text { Donald Livingstone } \mathrm{III}^{4} \cdot \text { Ray Schnell }}^{5} \cdot$ Brian Staskawicz $^{1,2}$. \\ Myeong-Je $\mathrm{Cho}^{1}$ (D)
}

Received: 23 March 2021 / Accepted: 31 May 2021/Published online: 15July2021 / Editor: Ted Klein

(C) The Author(s) 2021

\begin{abstract}
A highly efficient transformation protocol is a prerequisite to developing genetically modified and genome-edited crops. A tissue culture system spanning culture initiation from floral material to conversion of embryos to plants has been tested and improved in Theobroma cacao. Nine cultivars were screened for their tissue culture response and susceptibility to Agrobacterium transferDNA delivery as measured through transient expression. These key factors were used to determine the genetic transformability of various cultivars. The high-yielding, disease-resistant cultivar INIAPG-038 was selected for stable transformation and the method was further optimized. Multiple transgenic events were produced using two vectors containing both yellow fluorescent protein and neomycin phosphotransferase II genes. A two-fold strategy to improve both T-DNA delivery and secondary somatic embryogenesis rates was conducted to improve overall transformation frequency. The use of Agrobacterium strain AGL1 and cotyledon tissue derived from secondary somatic embryos ranging in size between 4 to $10 \mathrm{~mm}$ resulted in the highest T-DNA delivery efficiency. Furthermore, the use of higher concentrations of basal salts and cupric sulfate in the medium increased the frequency of explants producing greater than ten embryos by five-fold and four-fold during secondary somatic embryogenesis, respectively. Consequently, an optimal combination of all these components resulted in a successful transformation of INIAPG038 with $3.7 \%$ frequency at the $T_{0}$ plant-level. Grafting transgenic scions with undeveloped roots to non-transgenic seedlings with healthy roots helped make plantlets survive and facilitated quick transplantation to the soil. The presented strategy can be applied to improve tissue culture response and transformation frequency in other Theobroma cacao cultivars.
\end{abstract}

Keywords Theobroma cacao · Agrobacterium tumefaciens · Genetic transformation · Somatic embryogenesis · Regeneration · Grafting

Myeong-Je Cho

mjcho1223@berkeley.edu

1 Innovative Genomics Institute, University of California, Berkeley, CA, USA

2 Department of Plant and Microbial Biology, University of California, Berkeley, CA, USA

3 Mars Center for Cocoa Science, Bahia, Brazil

4 Mars Wrigley Plant Science Laboratory, Davis, CA, USA

5 Mars Cacao Laboratory, Miami, FL, USA

\section{Introduction}

Theobroma cacao L. is an economically important crop grown predominantly in Africa, although the species was originally domesticated in South America where significant production still remains. Despite Theobroma cacao beans being a commodity in a multibillion-dollar industry, there have been severe losses from disease to both crop yield and tree survival (Marelli et al. 2019). Obstacles such as long juvenile period, issues with heterozygous and heterogeneous populations (Wickramasuriya and Dunwell 2018), long life cycle, and funding constraints on conventional Theobroma cacao breeding programs (Gotsch 1997) make desired traits like high yield, disease resistance, and bean quality difficult to combine into a single cultivar. However, both genome editing and 
transgenic approaches can be used to improve and greatly accelerate the pace of trait development.

The first stable transformation to regenerate Theobroma cacao plants was reported by Maximova et al. (2003) and since then there have been only a few other successful reports of the transformation of TcChil (Maximova et al. 2006), TcLEC2 (Shires et al. 2017; Fister et al. 2018b), and D5C and pD4e1 (Mejía et al. 2012) into Theobroma cacao. Transient expression of CRISPR/Cas9 was also used to partially knockout TcNPR3 to improve defense response in Theobroma cacao (Fister et al. 2018a). The introduction of $B A B Y$ BOOM transcription factor into Theobroma cacao significantly increased transformation frequency, but it caused a regeneration issue with an abnormal phenotype (Florez et al. 2015). These previously mentioned experiments were performed on the amenable cultivar PSU SCA-6. Previous to this study, all reports published in the literature of transgenic plants being recovered were only in cultivar PSU SCA-6. Although PSU SCA-6 is not identical to SCA-6, the original SCA-6 was collected from the wild in the Peruvian Amazon (Zhang et al. 2011) and has some natural disease resistance (Pokou et al. 2019). However, this cultivar is not highly productive (Susilo et al. 2009). For genetic transformation to be used most effectively, the ability to transform many Theobroma cacao cultivars, including those less amenable to transformation, must be established. Ideally, a single genotype-independent transformation method would be developed, but similar to somatic embryogenesis which has had broad success across the plant kingdom, there still exists a high degree of genotype-to-genotype variation and so protocol customization is necessary (Garcia et al. 2016). Optimization of the basal salts, duration of hormone treatments, explant quality, and explant type are effective ways to improve the culturing response of recalcitrant cultivars.

Several explant types are used in Theobroma cacao tissue culture and the transformation process, which include petals and staminodes from unopened, immature flowers, cotyledon tissue from somatic embryos, and intact somatic embryos. Petals and staminodes are capable of primary somatic embryogenesis (Esan 1975; Li et al. 1998; Tan and Furtek 2003; da Silva et al. 2008; Garcia et al. 2016) and are the starting point for all subsequent processes. Cotyledon tissue derived from somatic embryos is an alternative tissue type and efficient at secondary, tertiary, and quaternary somatic embryogenic responses (Maximova et al. 2002). Mature somatic embryos undergo conversion to plantlets and are able to be transplanted to soil. So far, all previous transformation methods (Maximova et al. 2003, 2006; Florez et al. 2015; Shires et al. 2017) used an embryogenic approach utilizing cotyledon tissue from somatic embryos. The advantages to this approach include previously described methodologies, the predominant single-cell origin of embryos (Maximova et al. 2002), and the high number of embryos cotyledon tissue capable of producing. Alternatively, an organogenic approach was not thoroughly explored because of the lack of previously described methods in Theobroma cacao, the apparent difficulty of establishing a new tissue culture system, and the non-clonal nature of seed which would result in the loss of the original cultivar if used as an organogenic donor material.

In this study, we report a successful Agrobacterium-mediated transformation and regeneration protocol for INIAPG038, using improved somatic embryogenesis and Agrobacterium infection. INIAPG-038 is a breeding line developed by Mars Wrigley, Incorporated, in collaboration with United States Department of Agriculture (USDA) and Instituto Nacional de Investigaciones Agropecuarias (INIAP). It is a highly productive cultivar which has tolerance to fungal diseases such as frosty pod disease (Costa et al. 2012; Meinhardt et al. 2014) and witches broom disease (Mondego et al. 2008). We also demonstrate a method for evaluating how amenable a cultivar is to tissue culture and transformation as well as provide data on the cultivars we screened.

\section{Materials and Methods}

Plant material Nine Theobroma cacao cultivars, SCA-6, CCN-51, INIAPG-038, INIAPT-374, INIAPG-152, INIAPM-053, INIAPG-029, INIAPT-484, and Matina 1-6, were used for tissue culture response experiments. Unopened, immature flowers originated from USDA Agricultural Research Service Subtropical Horticulture Research Station in Miami, FL, where they were harvested from the greenhouse in the morning then shipped overnight to the Innovative Genomics Institute (IGI) Plant Genomics and Transformation Facility, Berkeley, CA. Cultivars were primarily chosen based on their consistent availability of flowers. The flowers were sealed within a 50-mL Falcon conical centrifuge tube which contained a $5 \mathrm{mM}$ dithiothreitol solution and shipped in a Styrofoam insulated box along with ice packs to maintain a temperature of approximately $4^{\circ} \mathrm{C}$.

Initiation of primary embryogenesis using flower material and improvements Immature flowers were used to initiate primary somatic embryos according to the previous protocols (Li et al. 1998; Garcia et al. 2016) with some modifications. The medium composition followed was that of Garcia et al. (2016). Explants of 9 cultivars were observed after 3 to 4 mo of culture to determine the rate at which both staminode and petal explants formed embryos; a brief summary of the method follows. To initiate flower material, it is surface-sterilized using a $20 \%(\mathrm{v} / \mathrm{v})$ bleach solution (final concentration of $1.05 \%$ sodium hypochlorite) containing $0.002 \%$ Tween 20 then dissected; the petals and staminodes are placed onto primary callus growth (PCG) medium for $2 \mathrm{wk}$ then transferred 
to secondary callus growth (SCG) medium (Garcia et al. 2016) for 2 wk, after which, it is transferred to ED4 (embryo development medium containing $4 \%$ sucrose, Garcia et al. (2016)) for $2 \mathrm{wk}$ then subsequently on ED3 (embryo development medium containing 3\% sucrose, Garcia et al. (2016)) where it remains until embryos have formed and observations made. The total amount of staminodes and petals used for each cultivar as well as the number of replicates for each cultivar varied; they are as follows: SCA-6 with 1879 total explants across 2 replicates, CCN-51 with 985 total explants across 6 replicates, INIAPG-038 with 716 total explants across 7 replicates, INIAPT-374 with 623 total explants across 4 replicates, INIAPG-152 with 395 total explants across 4 replicates, INIAPM-053 with 295 total explants across at 4 replicates, INIAPG-029 with 260 total explants across 4 replicates, INIAPT-484 with 281 total explants across at 4 replicates, and Matina 1-6 with 645 total explants across 4 replicates.

\section{Initiation of secondary somatic embryogenesis using primary} embryos To induce secondary somatic embryogenesis, cotyledons were excised from primary somatic embryos and dissected into 4- to $10-\mathrm{mm}$ segments. These explants were handled according to the method described by Maximova et al. (2002) and Garcia et al. (2016), although the SCG medium used was from the later. Secondary somatic embryos were harvested from these cultures while they were on ED3 and used for conversion to plantlets and Agrobacterium transformation. Initially, four cultivars, INIAPG-038, CCN-51, SCA6 , and INIAPT-374, were screened for the rates at which primary somatic embryo explants formed secondary somatic embryos. The embryos yielded from these explants were counted at approximately $10 \mathrm{wk}$ and each explant ranked into one of four ratings: no embryos produced, 1 to 4 embryos produced, 5 to 9 embryos produced, and $\geq 10$ embryos produced. The total amount of explants used for each cultivar as well as the number of replicates for each cultivar varied; they are as follows: INIAG-038 with 2698 explants across 9 replicates, CCN-51 with 791 explants across 7 replicates, SCA-6 with 2514 explants across 8 replicates, and INIAT-374 with 752 explants across 5 replicates.

Embryo conversion and plantlet regeneration Somatic embryos remained on ED3 medium until they were approximately 15 to $20 \mathrm{~mm}$ in length, at which point they were ready for conversion to plantlets. The conversion process began when these somatic embryos were placed onto ED6 medium (embryo development containing 6\% sucrose, Garcia et al. (2016)) and were exposed to low levels of light-emitting diode (LED) light, 10 to $30 \mu \mathrm{mol} \mathrm{m} \mathrm{m}^{-2} \mathrm{~s}^{-1}$. These embryos were incubated at $27^{\circ} \mathrm{C}$ and the Petri dishes were then wrapped with $3 \mathrm{M}$ Micropore tape (3M, St. Paul, MN) to allow for gas exchange. After 2 wk on ED6, the embryos were transferred to embryo development light (EDL) media (Li et al. 1998) and then maintained on EDL with transfers every 2 wk. As the cultures developed, they were slowly exposed to higher LED light intensities, 30 to $60 \mu \mathrm{mol} \mathrm{m}{ }^{-2} \mathrm{~s}^{-1}$. The conversion rates of various cultivars were measured and compared. An embryo was considered converted if it produced a shoot with a meristem and a root at least $1 \mathrm{~cm}$ in length. When the plantlets were $2.5 \mathrm{~cm}$ tall, they were transferred to a Phytatray $^{\mathrm{TM}}$ II (Sigma-Aldrich, St. Louis, MO) containing $100 \mathrm{~mL}$ of medium and sealed with $3 \mathrm{M}$ Micropore tape. The cultivars tested include INIAPT-374, CCN-51, and INIAPG-038. The total amount of embryos used for each cultivar as well as the number of replicates for each cultivar varied; they are as follows: INIAPT-374 with 256 embryos across 4 replicates, CCN-51 with 227 embryos across 8 replicates, and INIAPG-038 with 868 embryos across 9 replicates.

Transfer-DNA (T-DNA) delivery efficiency test Four cultivars, INIAPG-038, SCA-6, CCN-51, and INIAPT-374, were tested for transient fluorescent protein expression (FPE) after transformation. Two different binary vectors, pDDNPTYFP-1 and pDDNPTYFP-2, were used in Theobroma cacao transformation experiments (Fig. 1); pDDNPTYFP-1 contains neomycin phosphotransferase II (nptII)-GlyLink-enhanced yellow fluorescent protein (eyfp) translational fusion driven by the cauliflower mosaic virus 35S (CaMV35S) promoter (Fig. 1a) while pDDNPTYFP-2 contains two separate gene cassettes, $n p t I I$ driven by the enhanced CaMV35S promoter and eyfp driven by the Nos promoter/TMV $\Omega$ enhancer (Fig. 1b). Both vectors were built in the pCAMBIA2300 backbone. Secondary embryos of similar size, color, and morphology were selected from each cultivar and infected using the methods later described using the Agrobacterium strain AGL1. Explants were assessed based on FPE $7 \mathrm{~d}$ after Agrobacterium infection. Each explant was examined and ranked based on the percentage of its surface area that is expressing YFP. There were three rankings in total: 0 to $5 \%$ FPE coverage, 6 to $20 \%$ FPE coverage, and $>20 \%$ FPE coverage. The treatment with the greatest percent of explants with $>$ $20 \%$ FPE coverage was selected as the best; however, it was sometimes useful to consider the distribution throughout all the rankings. The total amount of explants used for each cultivar as well as the number of replicates for each cultivar varied; they are as follows: INIAPG-038 with 2025 explants across 16 replicates, $\mathrm{CCN}-51$ with 472 explants across 6 replicates, SCA-6 with 2905 explants across 10 replicates, and INIAPT-374 with 449 explants across 6 replicates.

T-DNA delivery and tissue culture improvements in INIAPG038 Four Agrobacterium strains, LBA4404, AGL1, EHA105, and GV3101, containing pDDNPTYFP-1 were tested for TDNA delivery efficiency. Three separate replicates comparing all 4 strains were conducted, the total explants used for each 
Figure 1 Schematic diagram of two transformation vectors used for Theobroma cacao $\mathrm{L}$. transformation. (a) pDDNPTYFP-1 is a 3637-bp TDNA fragment containing neomycin phosphotransferase II (nptII) and enhanced yellow fluorescent protein (eyfp) translational fusion driven by a CaMV35S promoter. (b) pDDNPTYFP-2 is a 4416-bp T-DNA fragment containing two gene cassettes where eyfp is driven by a Nos promoter/ TMV $\Omega$ enhancer and $n p t I I$ is driven by an enhanced CaMV35S promoter. a

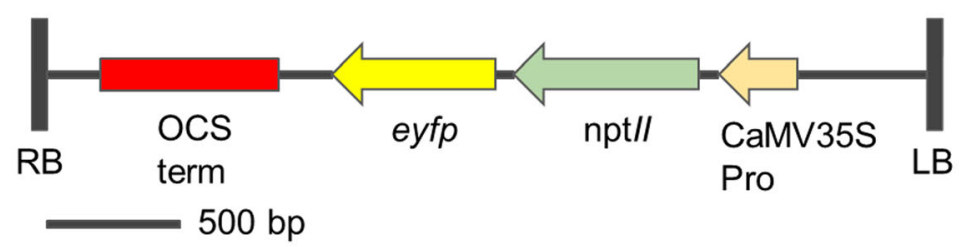

$\mathbf{b}$

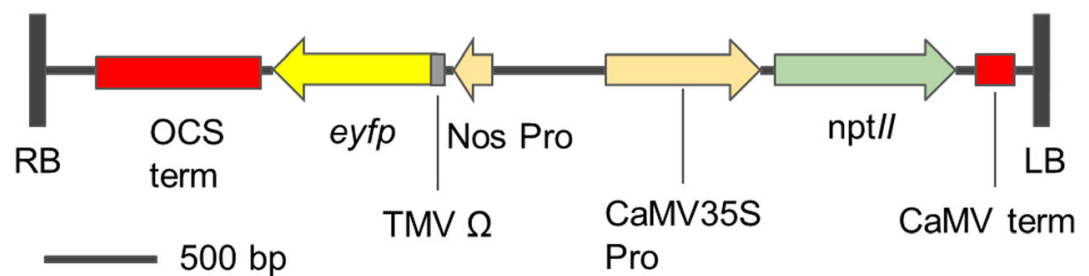

(enhanced) treatment of each replicate ranged from 130 to 200, and all material was sourced from INIAPG-038. All excised cotyledon tissue from the secondary somatic embryos was collected into a single Petri dish and randomized before being separated and treated with four different Agrobacterium strains. Prior to infection, each Agrobacterium strain was suspended into the infection medium and then diluted so that each Agrobacterium treatment was the same optical density at $600 \mathrm{~nm}$ wavelength $\left(\mathrm{OD}_{600 \mathrm{~nm}}\right)$. These experiments were evaluated based on FPE coverage at $1 \mathrm{wk}$ after infection using the method described previously.

The effect of secondary somatic embryo size on T-DNA delivery was also examined in INIAPG-038. Somatic embryos ranging in size between 4 to $10 \mathrm{~mm}$ were compared to somatic embryos 10 to $20 \mathrm{~mm}$. The total amount of explants used and number of replicates for each treatment are the following: 4 to $10 \mathrm{~mm}$ embryo size used 1007 explants across 9 replicates, and the 10 to $20 \mathrm{~mm}$ embryo size used 714 explants across 5 replicates. Explants were evaluated with the method described previously.

The effect of doubled woody plant medium (WPM) basal salt (Lloyd and McCown 1981) concentration as well as WPM adjusted to $5.0 \mu \mathrm{M}$ of $\mathrm{CuSO}_{4}$ in $\mathrm{SCG}$ was examined for their effect on secondary embryo production in INIAPG038. The treatments, total number of explants, and replicates are as follows: Standard 1× SCG medium evaluated with 198 explants across 3 replicates, $1 \times$ SCG containing additional $\mathrm{CuSO}_{4}$ evaluated with 327 explants across 5 replicates, and $2 \times$ SCG containing double concentration of WPM basal salts evaluated with 219 explants across 5 replicates. The explants were evaluated with the method described previously.

Stable Transformation of INIAPG-038 Transformations were performed using cotyledon tissue derived from somatic embryos of 4- to 10-mm length, white or tan in color, and with normal morphology. The donor material used for the transformation process was secondary somatic embryos, making the transformation a tertiary somatic embryogenic process. To prepare the explants, cotyledon tissue from the previously selected secondary embryos was excised then dissected into 4- to 10 -mm segments. The infection step was performed by suspending the explants in 10 to $20 \mathrm{~mL}$ of liquid medium harboring Agrobacterium contained within a sealed $50-\mathrm{mL}$ test tube. The infection medium consisted of MS basal salt and vitamins containing $200 \mu \mathrm{M}$ acetosyringone, $1 \mathrm{mg} \mathrm{L} \mathrm{L}^{-1}$ indoleacetic acid, and $2 \mathrm{mg} \mathrm{L}^{-1}$ zeatin. The Agrobacterium was thoroughly suspended in the liquid infection medium and the $\mathrm{OD}_{600 \mathrm{~nm}}$ was measured prior to use and adjusted to 0.400 . After 1 to $2 \mathrm{~h}$ of agitation, the Agrobacterium-infected cotyledon explants were transferred to a SCG-based co-cultivation medium and incubated at $21^{\circ} \mathrm{C}$ for $92 \pm 8 \mathrm{~h}$ before the Agrobacterium was washed away. To remove the Agrobacterium, the explants were transferred from cocultivation medium into a 50-mL Falcon conical centrifuge tube containing $5 \mathrm{~mL}$ of liquid SCG medium and agitated using a $1-\mathrm{mL}$ pipette for $1 \mathrm{~min}$, then the liquid SCG medium was decanted and additional $20 \mathrm{~mL}$ of liquid SCG medium was added and the tube was agitated for $1 \mathrm{~h}$ using an orbital shaker at $75 \mathrm{rpm}$. The cotyledon tissue was then transferred to a modified SCG medium containing $200 \mathrm{mg} \mathrm{L}^{-1}$ cefotaxime and $200 \mathrm{mg} \mathrm{L}^{-1}$ Timentin $^{\mathrm{TM}}$. The tissue remained on this antibiotic containing SCG for between 2 and 4 wk before transfer to ED4 medium containing the same antibiotics for another $2 \mathrm{wk}$; afterwards, the tissue was maintained on ED3 with antibiotics. Antibiotics remained in the medium whenever there were explants that had been directly exposed to Agrobacterium. However, later in the process during the conversion of quaternary somatic embryos, the antibiotics were removed from the medium. The first, second, and third transformations were conducted without the use of chemical 
selection and transgenic embryos were identified using visual marker selection. The fourth transformation included the use of $100 \mathrm{mg} \mathrm{L}^{-1}$ of kanamycin for chemical selection. After 2 wk of resting on SCG containing Timentin ${ }^{\mathrm{TM}}$ and cefotaxime but without kanamycin, the explants were moved to ED4 containing both antibiotics and kanamycin. This kanamycin concentration was maintained for $1 \mathrm{mo}$ then increased to $150 \mathrm{mg}$ $\mathrm{L}^{-1}$ while the explants were on ED3.

The Agrobacterium-infected tissue underwent indirect somatic embryogenesis and was observed using a fluorescent microscope multiple times between 1 and 4 mo during the formation of embryos. After the identification of a transgenic event through the use of the fluorescent microscope, the transgenic, tertiary somatic embryos (TSEs) were removed from the remainder of the non-transgenic tissue and isolated on ED3. To generate multiple quaternary somatic embryos (QSEs) from a single transgenic TSE, an additional somatic embryogenesis step was used. This additional somatic embryogenesis step follows the same method for generating secondary somatic embryos; cotyledons are dissected and placed onto SCG for 2 wk then ED4 for 2wk then maintained on ED3. QSE conversion and plantlet regeneration were conducted as described above.

PCR analysis A CTAB DNA extraction protocol, described by Murray and Thompson (1980), was used to extract genomic DNA from leaf materials of non-transgenic INIAPG-038 and transgenic INIAPG-038 plants. To test the presence of $n p t I I$ in transgenic plants, the primer set, NPTII 3F (5'-CAAG ATGGATTGCACGCAGGTT-3') and NPTII 4R (5'-TAGA AGGCGATGCGCTGCGAAT-3'), was used while the presence of eyfp was determined using the primer set, EYFP $3 \mathrm{~F}$ (5'-TAAACGGCCACAAGTTCAGCG-3') and EYFP 4R (5'-AGGACCATGTGATCGCGCTTC-3'). To test for the possible presence of Agrobacterium contamination in the extracted DNA samples or a read-through event, two genes on the Agrobacterium backbone were also tested for. The presence of pVS1 was tested for using the primer set PVS1 $1 \mathrm{~F}\left(5^{\prime}\right.$ ATGAAGGTTATCGCTGTACT-3') and PVS1 2R (5'CTGATTCAAGAACGGTTGTG-3') while the presence of $n p t 1$ was tested for using the primer set NPT1 1F (5'-CTCC TGCTAAGGTATATAAGC-3') and NPT1 2R (5'-AATC AGGCTTGATCCCCAGT-3'). For each PCR reaction mixture, the following reagents were used: $25 \mu \mathrm{L}$ DreamTaq PCR Master Mix (2×) (Thermo Fisher Scientific, Grand Island, $\mathrm{NY}), 1.0 \mu \mathrm{L}$ forward primer at $10 \mu \mathrm{M}, 1.0 \mu \mathrm{L}$ reverse primer at $10 \mu \mathrm{M}$ and $21 \mu \mathrm{L} \mathrm{H}_{2} 0$, and $2.0 \mu \mathrm{L}$ genomic DNA at approximately $100 \mathrm{ng} \mu \mathrm{L}^{-1}$, for a total volume of $50 \mu \mathrm{L}$. The PCR was carried out with the following thermal cycler programming: hold at $95^{\circ} \mathrm{C}$ for $3 \mathrm{~min}, 16$ cycles of $94^{\circ} \mathrm{C}$ for $30 \mathrm{~s}$, $58^{\circ} \mathrm{C}$ for $30 \mathrm{~s}\left(-0.5^{\circ} \mathrm{C} /\right.$ cycle $), 68^{\circ} \mathrm{C}$ for $1 \mathrm{~min}, 50$ cycles of $94^{\circ} \mathrm{C}$ for $30 \mathrm{~s}, 54^{\circ} \mathrm{C}$ for $30 \mathrm{~s}$, and $69^{\circ} \mathrm{C}$ for $1 \mathrm{~min}$, and then elongation at $68^{\circ} \mathrm{C}$ for $7 \mathrm{~min}$, and remained at $4^{\circ} \mathrm{C}$ for infinite.
For each PCR reaction, $20 \mu \mathrm{L}$ was loaded onto a $0.8 \%$ agarose gel for electrophoresis.

Fluorescent visualization Fluorescent images of embryos and plantlets of transgenic INIAPG-038 events were visualized with a fluorescent Leica M165 FC stereomicroscope, equipped with Leica DFC7000 T (JH Technologies, Fremont, CA), using two microscopic filters, bright field and ET YFP with $514 \mathrm{~nm}$ excitation and $527 \mathrm{~nm}$ emission. The microscope is linked to a camera imaging software, Leica Application Suite version 4.9, which was used to capture the fluorescent images. Screening of fluorescent activity was measured at $30 \times$ magnification.

Transplantation to soil and acclimatization After embryo conversion while the plantlets are 10 to $13 \mathrm{~cm}$ in height and have 6 to 10 leaves, they were transferred to soil. The plantlets were transferred into a well-draining soil, mixing equal parts Sun Gro $^{\mathrm{TM}}$ potting mix (Sun Gro Horticulture Distribution Inc., Agawam, MA) and perlite was found to work well. When transplanting, the agar was removed by hand and by dipping the roots into water. The plantlets were then planted into square 4-inch pots with pre-moistened soil mix and immediately placed in a 1020 water tray (Greenhouse Megastore, West Sacramento, CA) then covered with a 7 -inch vented humidity dome (Greenhouse Megastore) with all vents closed. On top of the humidity dome, shades were placed to reduce the light intensity to $60 \mu \mathrm{mol} \mathrm{m} \mathrm{m}^{-2} \mathrm{~s}^{-1}$. The tray, humidity dome, shades, and plants were kept inside a Conviron plant growth chamber with the parameters described later. Over the course of $1 \mathrm{wk}$, the vents on the humidity dome were opened and the shades were removed. After this acclimatization process, the plants were able to survive in the growth chamber with an ambient environment of $27^{\circ} \mathrm{C}, 60$ to $70 \% \mathrm{RH}$, and 120 to $180 \mu \mathrm{mol} \mathrm{m}{ }^{-2} \mathrm{~s}^{-1}$ light intensity.

Grafting of transgenic scions onto in vitro germinated rootstock Wedge-shaped grafting was done as previously described by Bezdicek et al. (1972) with modifications. Theobroma cacao pods of an unspecified Amelonado group (GRIN accession \# PI 668412) were surface-sterilized using $10 \%$ (v/v) bleach solution (final concentration of $0.525 \%$ sodium hypochlorite) for $15 \mathrm{~min}$, then the pod was cut open and the seeds removed. The thick pulp was then removed from the seeds. The seeds were further surface-sterilized using $10 \%$ $(\mathrm{v} / \mathrm{v})$ bleach solution (final concentration of $0.525 \%$ sodium hypochlorite) for $15 \mathrm{~min}$. The sterilized seeds were then soaked in sterile water for $72 \mathrm{~h}$. Afterwards, these pregerminated seeds were planted into autoclave-sterilized peat pellets (Jiffy Products of America Inc. Lorain, $\mathrm{OH}$ ) soaked in a liquid EDL medium. The seedlings were kept in Phytatray ${ }^{\mathrm{TM}} \mathrm{II}$ and cultured similar to tissue culture-derived plantlets. 
When both a transgenic scion with poor roots and a nontransgenic in vitro root stock with strong, healthy roots were available, grafting was performed using a "V" shape cut similar to a saddle or cleft graft on the seedling and two diagonal cuts exposing the cambium layer of the transgenic scion. The scion and rootstock were then combined and secured using both a paper clip and a 1-cm segment of a polypropylene straw cut down the side to resemble a "C." All the cuts were performed and secured using sterilized tools and materials. The grafts were then sealed in Phytatray ${ }^{\mathrm{TM}}$ II with micropore tape and liquid EDL medium was periodically added to maintain proper moisture. After the scion and rootstock fused, they were transplanted to the soil using the previously outlined method.

\section{Results and Discussion}

To establish a successful, highly efficient transformation protocol, a tissue culture system spanning the initiation of floral material to the regeneration of plantlets into soil has been tested and improved in Theobroma cacao. Multiple cultivars were screened for their response to (1) primary embryo induction from floral material, (2) secondary embryo production from cotyledon tissue derived from primary somatic embryos, (3) embryo conversion to plantlets, and (4) T-DNA delivery efficiency via Agrobacterium. These four factors were used to determine how amenable various cultivars would be for genetic transformation.

Tissue culture response and INIAPG-038 improvements Petals and staminodes were used to initially test somatic embryogenesis in nine Theobroma cacao cultivars. Staminode explants generally formed embryos at a higher frequency than petal explants in all cultivars except SCA-6 where they were equal (Fig. 2). This is consistent with previous observations made by Tan and Furtek (2003) and Traore and Guiltinan (2006). However, Garcia et al. (2016) observed that SCA-6 petals produced on average more embryos per explant than staminodes. The cultivar with the highest percentage of floral explants forming embryos was SCA- 6 with $44 \%$ of petals and $44 \%$ of staminodes forming embryos (Fig. 2). The next best performing cultivars were $\mathrm{CCN}-51$ with $6 \%$ of petals and $29 \%$ of staminodes, and INIAPT-374 with $4 \%$ of petals and $21 \%$ of staminodes and INIAPG-038 with $7 \%$ of petals and $15 \%$ of staminodes producing embryos at their respective rates. The remainder of the cultivars had less than $10 \%$ of floral explants producing embryos with INIAPG-152 and INIAPM-053 performing slightly better than the more recalcitrant INIAPT-484, INIAPG-029, and Matina 1-6.

The four cultivars, SCA- 6 , CCN-51, INIAPT-374, and INIAPG-038, showing the best primary somatic embryo formation (Fig. 2) were further tested for their secondary somatic embryo production (Fig. $3 a$ ). It was observed that INIAPG038 had the highest percentage of explants producing greater than 10 embryos at $6.2 \%$. It also had the greatest number of explants producing between 5 and 9 embryos at $12.6 \%$. SCA6 and CCN-51 had similar secondary embryo production to INIAPG-038 while INIAPT-374 was lowest in secondary embryo production with $1.0 \%$ and $2.8 \%$ of explants forming greater than 10 embryos and percent of explants forming between 5 and 9 embryos, respectively. In total, three cultivars were tested for the rate at which embryos would regenerate into plantlets (Fig. 3b). INIAPT-374 had embryo regeneration rates of $33 \%$. CCN-51 and INIAPG-038 embryos regenerated to plantlets at a rate of $28 \%$ and $22 \%$, respectively. However, there was no significant difference among these 3 cultivars.

With regard to experiments conducted to improve secondary somatic embryogenesis in INIAPG-038, it was observed that using a 2-fold concentration of WPM basal salts or WPM adjusted to $5.0 \mu \mathrm{M}$ of $\mathrm{CuSO}_{4}$ in $\mathrm{SCG}$ performed better than the standard SCG medium containing 1-fold WPM basal salts (Fig. 4). The standard SCG had $2.5 \%$ of explants forming greater than 10 embryos and $12.0 \%$ forming between 5 and 9 embryos, whereas 2-fold WPM basal medium resulted in $12.3 \%$ and $16.5 \%$, respectively. The 2-fold WPM basal medium was significantly higher in percentage of explants forming greater than 10 embryos produced, compared to the standard SCG medium. The standard SCG medium, WPMbased medium, contains $1.0 \mu \mathrm{M} \mathrm{CuSO} 4,10$-fold higher than MS medium (Murashige and Skoog 1962). A five-fold copper level $(5.0 \mu \mathrm{M})$ in SCG medium resulted in $10.9 \%$ of explants producing greater than 10 embryos and $23.4 \%$ of explants forming 5 to 9 embryos in INIAPG-038 (Fig. 4); it was significantly higher in percentage of explants forming greater than 10 embryos produced and significantly lower in percentage of explants forming no embryos produced, compared to the standard SCG medium. This is consistent with the previous conclusion that the callus quality, callus growth, and regenerability can be improved by increasing level of the micronutrient copper in barley and oat (Dahleen 1995; Cho et al. 1998, 1999).

T-DNA delivery efficiency improvements and optimizations Experiments for the T-DNA delivery efficiency test were conducted using pDDNPTYFP-1 containing $n p t I I:: e y f p$ in the 4 cultivars with good tissue culture response: INIAPG-038, CCN-51, SCA-6, and INIAPT-374 (Fig. 5). Out of them, INIAPG-038 and CCN-51 had the T-DNA delivery efficiency with $16 \%$ and $14 \%$ of explants having $>20 \%$ FPE coverage, respectively. The other 2 cultivars, SCA- 6 with $9 \%$ and INAPT-374 with $6 \%$ of explants, ranked as $>20 \%$ FPE coverage.

Of the four Agrobacterium strains tested, AGL1 and EHA105 produced the highest transient FPE coverage in INIAPG-038. Both LBA4404 and GV3101 performed poorly 
Figure 2 Somatic embryo formation from flower materials for 9 different Theobroma cacao L. cultivars. Petal and staminode explants were used to induce primary somatic embryos. Each histogram represents the mean level ( \pm standard error).

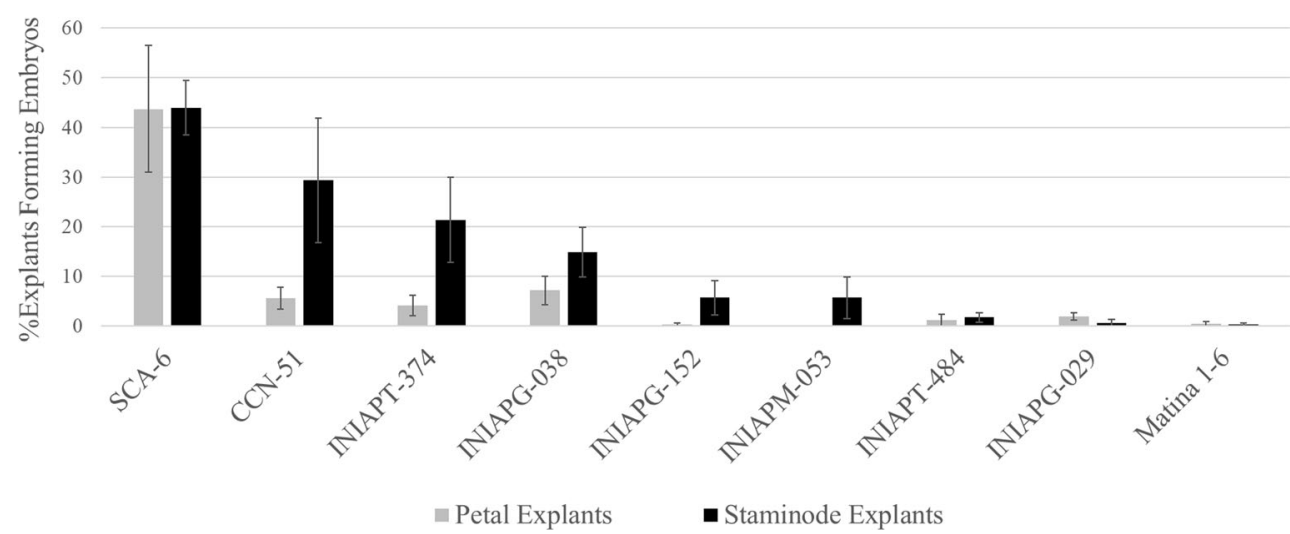

in T-DNA delivery efficiency (Fig. 6). The Agrobacterium strain AGL1 produced an average of $13 \%$ of explants ranked at $>20 \%$ FPE, while EHA105 produced an average of $12 \%$. GV3101 produced an average of $4 \%$ of explants ranked at $>$ $20 \%$ FPE, while LBA4404 produced an average of $3 \%$. The Agrobacterium strain AGL1 producing a higher transformation frequency was previously observed in stable transformation of an elite maize inbred (Cho et al. 2014). However, other plant species or explants favored different Agrobacterium strains such as LBA4404 used in tobacco transformation (Bakhsh et al. 2014) and GV3101 used in tomato transformation (Chetty et al. 2013).

With regard to the INIAPG-038 explant type used for Theobroma cacao transformation, we observed that cotyledon tissue derived from primary or secondary somatic embryos had the highest transient FPE, while hypocotyl and radicle explants demonstrated very little transient FPE and embryo production after Agrobacterium infection (data not shown). Previously cotyledon tissues derived from mature embryos of PSU SCA-6 were used for transformation target

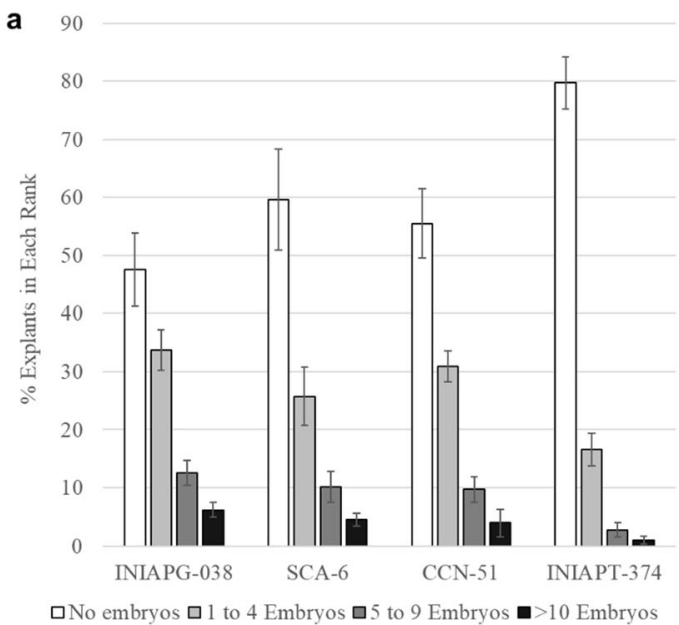

Figure 3 Secondary somatic embryogenesis and embryo conversion to plantlets for selected Theobroma cacao L. cultivars. (a) Cotyledon explants were observed in four ranks based on the number of embryos they produced: No embryos produced, 1 to 4 embryos produced, 5 to 9 embryos produced, and greater than 10 embryos produced. (b) Mature
(Maximova et al. 2003, 2006; Florez et al. 2015; Shires et al. 2017). Our study showed that the embryo size of INIAPG-038 also affected transient FPE after transformation (Fig. 7). Cotyledon tissues derived from immature somatic embryos ranging in size between 4 to $10 \mathrm{~mm}$ outperformed those derived from mature embryos ranging in size between 10 to $20 \mathrm{~mm}$. It was observed that embryos ranging in the 4 to $10 \mathrm{~mm}$ range produced explants with $>20 \%$ FPE coverage at a rate of $19 \%$, whereas 10 to $20 \mathrm{~mm}$ embryos only produced explants with $>20 \%$ FPE coverage at a rate $6 \%$.

Stable transformation of INIAPG-038 INIAPG-038 was selected for further improvements to tissue culture response, TDNA delivery efficiency, and eventually for stable transformation because it performed the best in both secondary somatic embryogenesis and T-DNA delivery. Although out of the 4 best cultivars from primary somatic embryogenesis screening, it performed less efficiently in primary somatic embryogenesis (Fig. 2); this step is not as crucial for transformation and is not seen as a potential bottleneck. In addition,

b

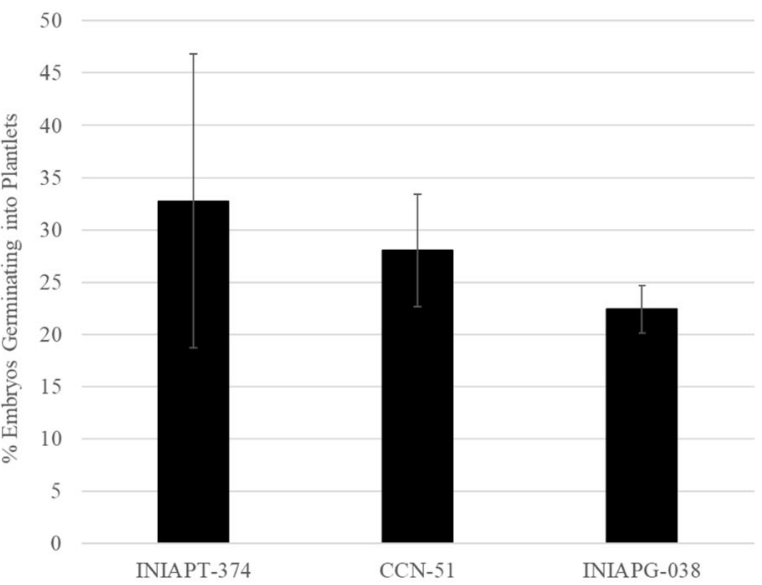

embryos were exposed to increasing levels of light while on embryo development medium containing $6 \%$ sucrose then embryo development light medium and counted as converted if they produced a $1-\mathrm{cm}$ shoot with meristem and a root of $1 \mathrm{~cm}$. Each histogram represents the mean level ( \pm standard error). 


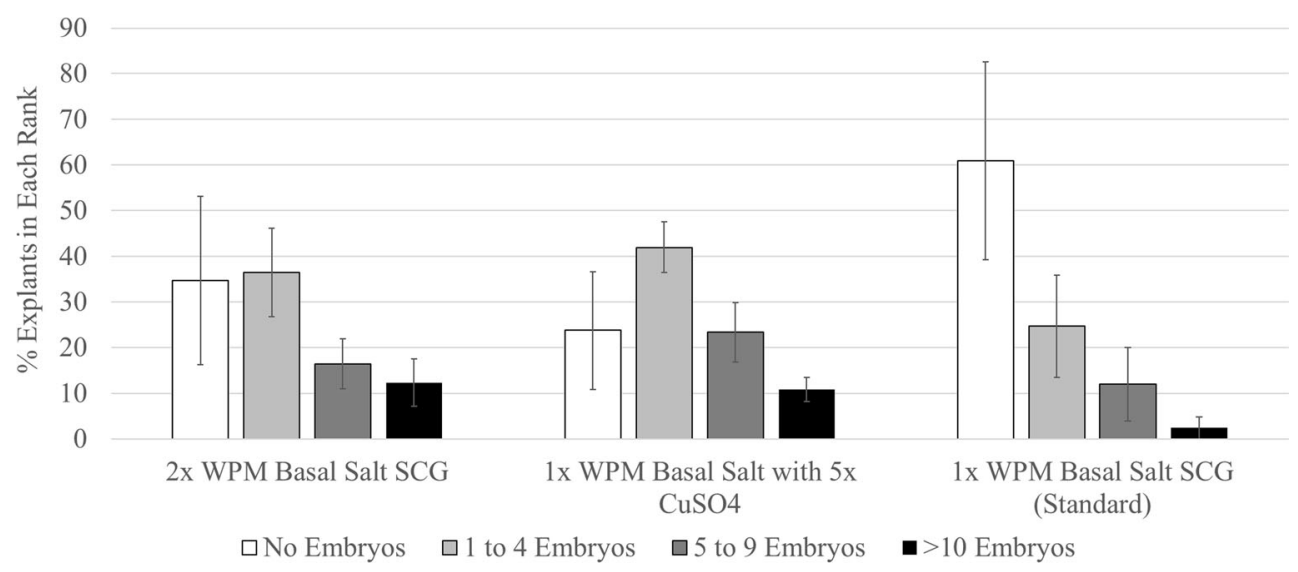

Figure 4 Effect of doubled woody plant medium (WPM) basal salt concentration and WPM adjusted to $5.0 \mu \mathrm{M}$ of $\mathrm{CuSO}_{4}$ in secondary callus generation (SCG) medium on secondary somatic embryogenesis in Theobroma cacao L. cv. INIAPG-038. Cotyledon explants were

observed in four ranks based on the number of embryos they produced: No embryos produced, 1 to 4 embryos produced, 5 to 9 embryos produced, and greater than 10 embryos produced. Each histogram represents the mean level ( \pm standard error).

INIAPG-038 is a highly productive cultivar with tolerance to frosty pod disease and witches broom disease. Previous transformations were conducted on PSU SCA-6 (Maximova et al. 2003, 2006; Florez et al. 2015; Shires et al. 2017) because it is an amenable cultivar with high somatic embryogenesis and genetic transformation potential (Maximova et al. 2006). This Forastero cultivar also demonstrates high production of primary somatic embryos when compared to Trinitario cultivars (Traore and Guiltinan 2006). Our decision to focus on INIAPG-038 was heavily weighed on the importance of the cultivar as well as the somatic embryogenic potential (Figs. 2 and $3 a$ ) and the T-DNA delivery efficiency (Fig. 5).

Stable transformation experiments in INIAPG-038 were conducted by infecting cotyledon tissues derived from the secondary somatic embryos with AGL1 containing pDDNPTYFP-1 or pDDNPTYFP-2 (Fig. 1). Six to ten cotyledon explants could be dissected from each embryo used in this process. Transient YFP expression was clearly observed 5 to $7 \mathrm{~d}$ after Agrobacterium infection (Fig. 8a). Five separate successful stable transformation experiments in INIAPG-038 were conducted by YFP visual marker selection. Kanamycin

selection was not tight enough and non-transgenic embryo tissue still formed on the cotyledon explants even with a high level of kanamycin. In the method described by Maximova et al. (2003) $50 \mathrm{mg} \mathrm{L}^{-1}$ of Geneticin ${ }^{\mathrm{TM}}$ (G418) for $n p t \mathrm{II}$ was used which greatly reduced the formation of non-transgenic tissues. Eight independent transformation events in the form of YFP-expressing globular embryos of INIAPG-038 were generated from the first 4 sets of experiments using cotyledon tissues derived from 82 somatic embryos; transformation frequency at the $\mathrm{T}_{0}$ tissue-level was $9.8 \%$ (8 out of 82 ) (Table 1, Fig. $8 b$ ). Eleven more independent transformation events were generated using 82 additional somatic embryos in the 5th set of experiments; transformation frequency at the $\mathrm{T}_{0}$ tissuelevel was $13.4 \%$ (11 out of 82 ) (Table 1).

The transformation process described in this paper yields only a single transgenic TSE (Fig $8 b$ ) for every transformation event and the average rate of embryo conversion for INIAPG038 is only $22.4 \%$ (Fig. $3 b$ ), so if one tried to regenerate transgenic TSEs directly, most transformation events would not be recovered as plants. To increase the probability of regenerating transformation events into plants, an additional

FIGURE 5 Transient yellow fluorescent protein (YFP) expression for selected Theobroma cacao L. cultivars. Cotyledon explants were observed in three ranks based on fluorescent protein expression (FPE) coverage: 0 to $5 \%$ FPE coverage, 6 to $20 \%$ FPE coverage, $>20 \%$ FPE coverage. Each histogram represents the mean level ( \pm standard error).

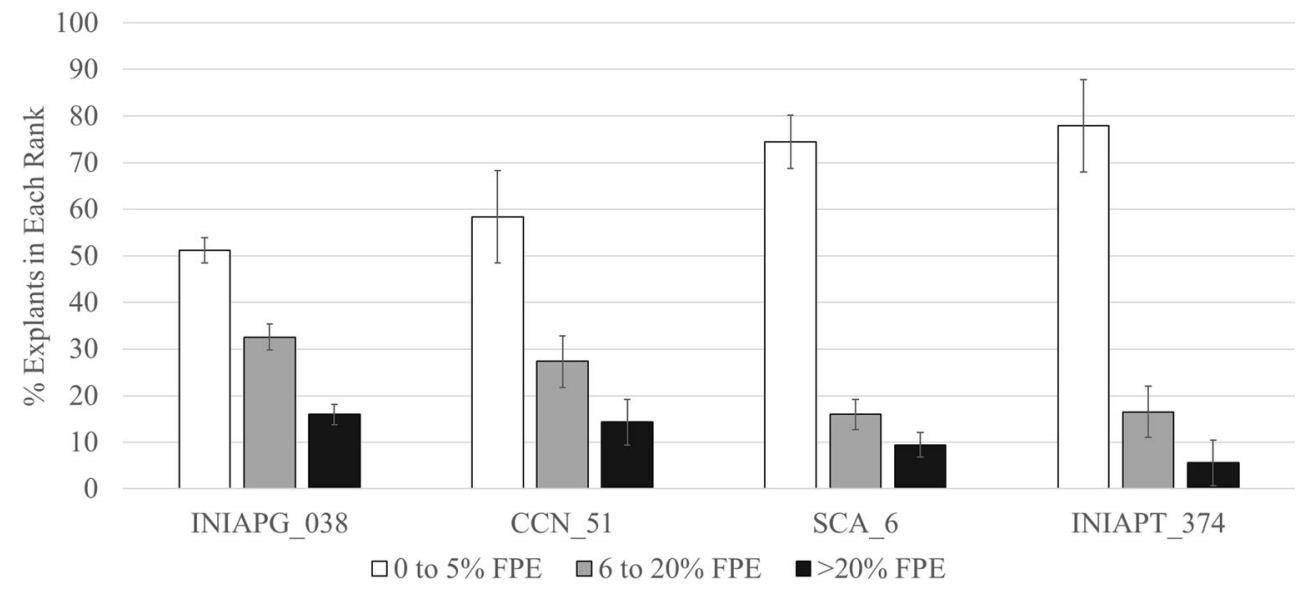


Figure 6 Effect of Agrobacterium strain on transient yellow fluorescent protein (YFP) expression in Theobroma cacao L. cv. INIAPG-038. Cotyledon explants were observed in three ranks based on fluorescent protein expression (FPE) coverage: 0 to $5 \%$ FPE coverage, 6 to $20 \%$ FPE coverage, $>20 \%$ FPE coverage. Each histogram represents the mean level ( \pm standard error).

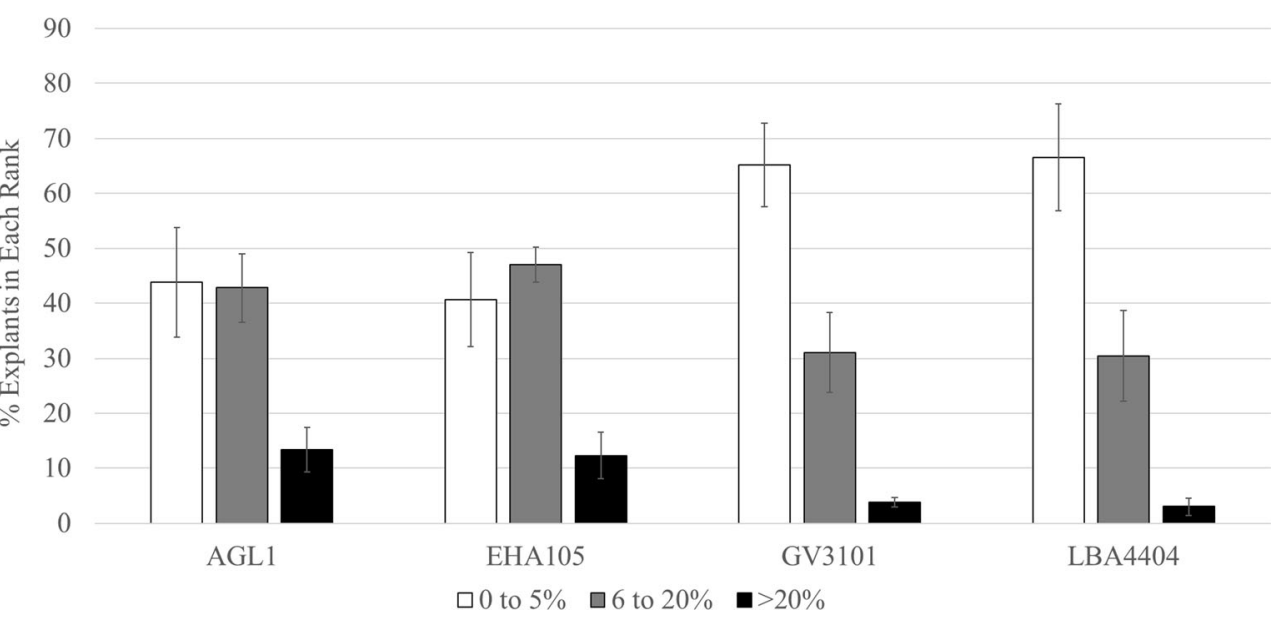

embryogenesis cycle was conducted to generate multiple transgenic QSEs from every transformation event prior to the embryo conversion step. Similarly, Maximova et al. (2003) also used an additional embryogenesis step after the production of transformation events to proliferate the number of somatic embryos from each transformation event. Of the 8 transformation events generated from the first 4 sets of transformation experiments, 3 transgenic TSEs developed into mature embryos (Fig. 8c) which were proliferated into multiple QSEs (Fig. 8d) and were capable of regeneration into plantlets (Fig. 8e), resulting in a $\mathrm{T}_{0}$ plant-level transformation frequency of $3.7 \%$ ( 3 out of 82 ) (Table 1). $\mathrm{T}_{0}$ transformation frequency was calculated as (\# of regenerable events/\# of embryos dissected) $\times 100 \%$. With quaternary somatic embryogenesis, all three of the transgenic events, \#1, \#2, and \#3, proliferated into 68,16 , and 95 total embryos, respectively (Table 1). One (event \#3) of the three transgenic embryos was chimeric and non-transgenic QSEs were discarded based on YFP expression. Of the QSEs generated for each event 15, 4, and 20 of those embryos converted into plantlets, respectively (Table 1), giving an average of $21.8 \%$ rate of transgenic embryo conversion to plantlets. Of the embryos converted to plants for each event 11,3 , and 3 plants of each event were successfully acclimatized in soil, respectively (Table 1 and Fig. 8f).
Some regenerated transgenic INIAPG-038 plantlets had slow or poor development of roots and these could not survive in soil; therefore, grafting was attempted to resolve this issue. Plantlets with poorly developed root systems routinely die during transplanting to soil; there is also a risk of damaging well-established root systems during agar removal. However, grafting transgenic scions in vitro avoids these two issues since a robust well-rooted non-transgenic seedling is used and the entire intact root system within a sterilized Jiffy peat cube can be placed into the soil without disturbing the roots (Fig. 8g). In total, six transgenic scions with poor roots were grafted onto rootstock; four of these grafts survived. Out of them, 1 plant of event \#3 was transferred to soil to grow in the greenhouse (Table 1). In addition, grafting could facilitate the use of transgenic shoots that might otherwise not form roots. The use of grafting to overcome poor in vitro rooting and improve transformant recovery was also used previously in safflower and cotton (Jin et al. 2006; Belide et al. 2011).

The presence of transgenes, eyfp and $n p t I I$, was confirmed by PCR analysis. The amplified product of $595 \mathrm{bp}$ corresponding to the internal fragment of eyfp gene was observed from genomic DNA of all 9 tested transgenic plants derived from three independent events using eyfp gene-specific primers, EYFP 3F and EYFP 4R (Fig. 9a). An amplified
FiguRE 7 Effect of somatic embryo size on transient yellow fluorescent protein (YFP) expression in Theobroma cacao L. cv. INIAPG-038. Cotyledon tissue derived from somatic embryos was used for experiments. Cotyledon explants were observed in three ranks based on fluorescent protein expression (FPE) coverage: 0 to $5 \%$ FPE coverage, 6 to $20 \%$ FPE coverage, $>20 \%$ FPE coverage. Each histogram represents the mean level ( \pm standard error).

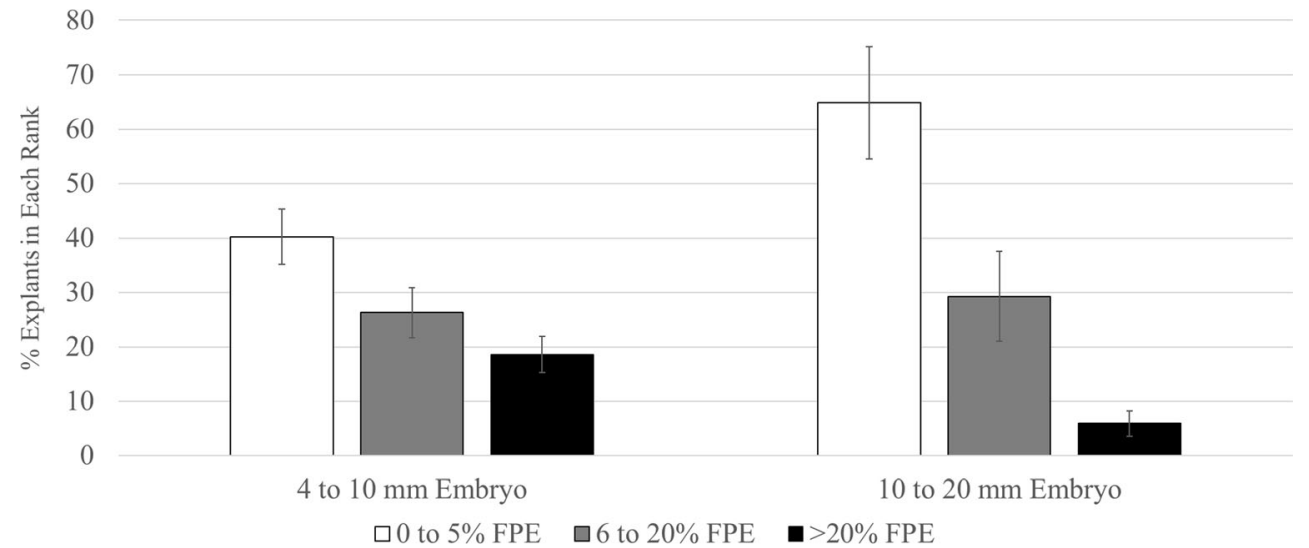


Table 1 Stable transformation frequencies of Theobroma cacao cv. INIAPG-038

\begin{tabular}{|c|c|c|c|c|c|c|c|c|c|}
\hline $\begin{array}{l}\text { Transformation } \\
\text { experiments }\end{array}$ & Vector used & $\begin{array}{l}\text { Number } \\
\text { of } \\
\text { embryos } \\
\text { dissected }^{\mathrm{a}}\end{array}$ & $\begin{array}{l}\text { Number of } \\
\text { YFP- } \\
\text { expressing } \\
\text { events }\end{array}$ & $\begin{array}{l}\mathrm{T}_{0} \text { tissue-level } \\
\text { transformation } \\
\text { frequency }\end{array}$ & $\begin{array}{l}\text { Number of } \\
\text { regenerable } \\
\text { events }\end{array}$ & $\begin{array}{l}\mathrm{T}_{0} \text { plant-level } \\
\text { transformation } \\
\text { frequency }{ }^{\mathrm{c}}\end{array}$ & $\begin{array}{l}\text { Number of } \\
\text { quaternary } \\
\text { somatic } \\
\text { embryos } \\
\text { produced }\end{array}$ & $\begin{array}{l}\text { Number of } \\
\text { plantlets } \\
\text { regenerated }\end{array}$ & $\begin{array}{l}\text { Number } \\
\text { of } \\
\text { plantlets } \\
\text { in soil }\end{array}$ \\
\hline Set 1 & pDDNPTYFP-1 & 32 & 2 & $6.3 \%$ & 1 & $3.1 \%$ & 68 & 15 & 11 \\
\hline Set 2 & pDDNPTYFP-2 & 10 & 1 & $10.0 \%$ & 0 & $0.0 \%$ & 0 & 0 & 0 \\
\hline Set 3 & pDDNPTYFP-2 & 24 & 3 & $12.5 \%$ & 1 & $4.2 \%$ & 16 & 4 & 3 \\
\hline \multirow[t]{2}{*}{ Set 4} & pDDNPTYFP-2 & 16 & 2 & $12.5 \%$ & 1 & $6.3 \%$ & 95 & 20 & $3(1)^{\mathrm{d}}$ \\
\hline & Subtotal & 82 & 8 & $9.8 \%$ & 3 & $3.7 \%$ & 179 & 39 & 17 \\
\hline \multirow[t]{2}{*}{ Set 5} & pDDNPTYFP-2 & 82 & 11 & $13.4 \%$ & n.d. & n.d. & n.d. & n.d. & n.d. \\
\hline & Total & 164 & 19 & $11.6 \%$ & & & & & \\
\hline
\end{tabular}

${ }^{a}$ After dissection, a somatic embryo would produce 6 to 10 cotyledon explants

${ }^{\mathrm{b}} \mathrm{T}_{0}$ tissue-level transformation frequency $=$ (number of YFP-expressing events/number of embryos dissected) $\times 100 \%$

${ }^{\mathrm{c}} \mathrm{T}_{0}$ plant-level transformation frequency $=$ (number of regenerable events/ number of embryos dissected) $\times 100 \%$

${ }^{\mathrm{d}}$ One out of 3 is a grafted plant and moved to soil to grow in the greenhouse

n.d., not determined

fragment of 761 bp was also observed from all tested transgenic plants derived from three independent events using $n p t \mathrm{II}$ gene-specific primers, NPTII 3F and NPTII 4R (Fig. 9b). No PCR-amplified eyfp and $n p t \mathrm{II}$ fragments were detected in the non-transgenic control plant (Fig. 9a, b) as expected. Additional PCR controls were performed using primers for the bacterial pVS1 origin of replication and $n p t I$ gene located outside the T-DNA borders to check the possibility of
Agrobacterium contamination giving false-positive results. The absence of transgenes, pvs 1 and npt1, was confirmed by PCR analysis in both the first and second events; however, the third event produced amplified products corresponding to two Agrobacterium vector backbone sequences (Fig. 9c, d). Comparisons of the two Agrobacterium strains used for transformation as well as intact leaf samples from the third event were compared to determine if Agrobacterium contamination
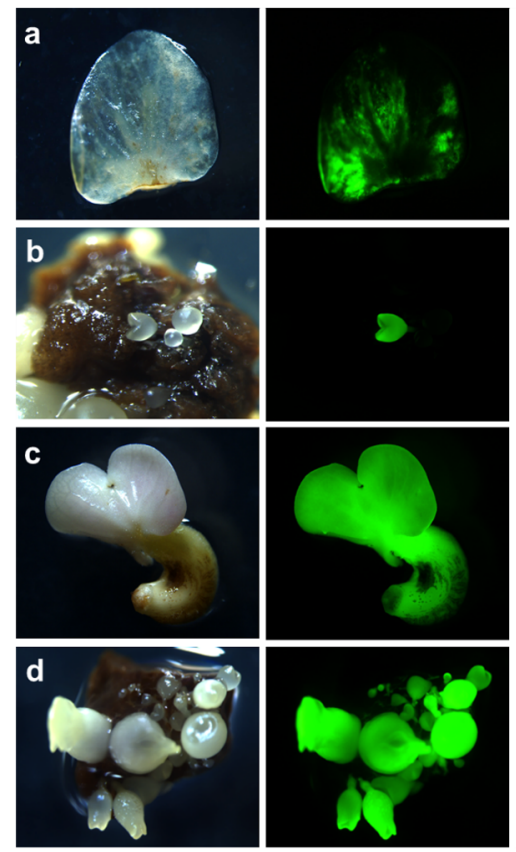

Figure 8 Transient yellow fluorescent protein (YFP) expression and stable transgenic event development in Theobroma cacao L. cv. INIAPG038. (a) Cotyledon expressing transient YFP. (b) YFP-expressing globular embryo. $(c)$ YFP-expressing mature embryo. $(d)$ YFP-expressing quaternary somatic embryos. (e) YFP-expressing plantlet. $(f)$ A non-
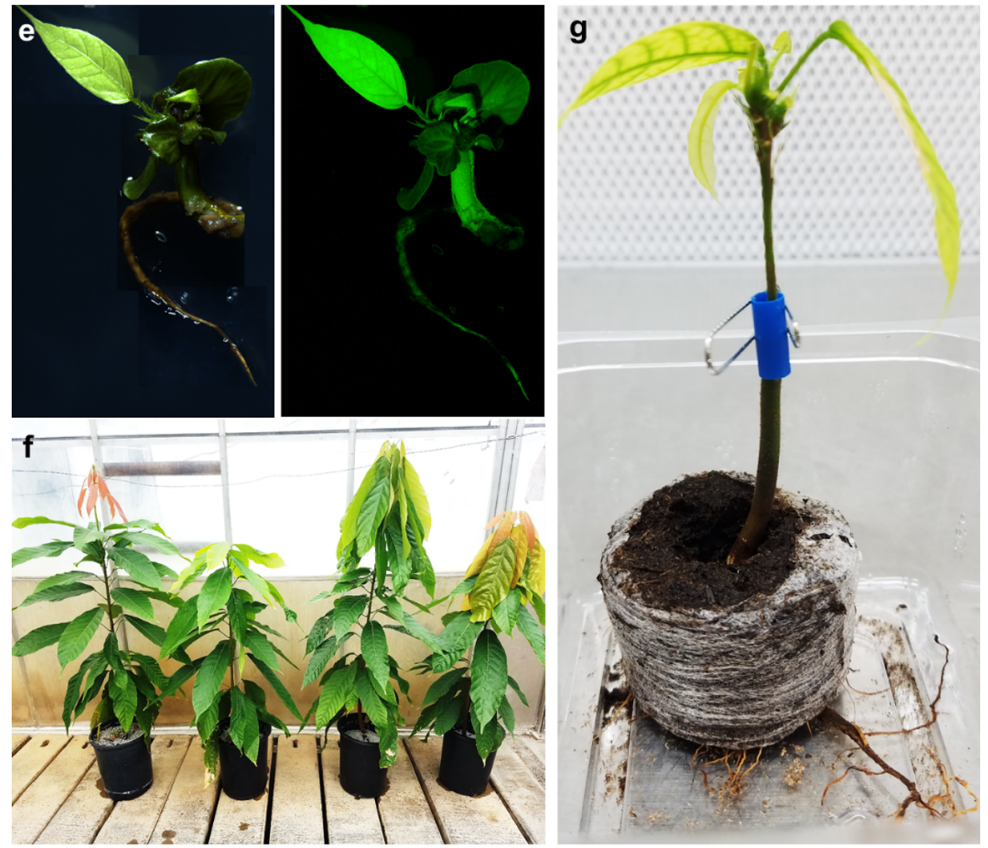

transgenic (left-most) and 3 transgenic INIAPG-038 plants in the greenhouse. $(g)$ A grafted transgenic INIAPG-038 plantlet in a Jiffy peat pellet; a transgenic INIAPG-038 scion with poor roots was grafted onto a nontransgenic rootstock. 


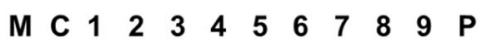

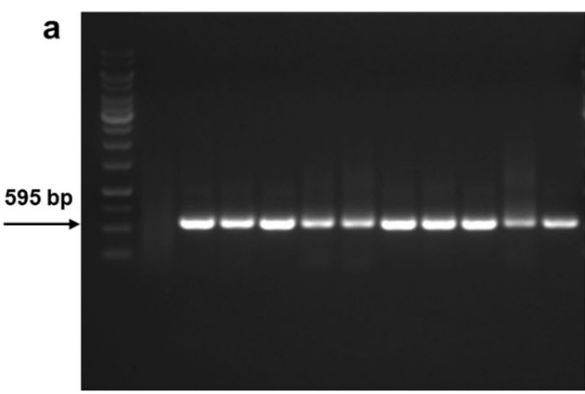

$\begin{array}{llllllllllll}\text { M } & C & 1 & 2 & 3 & 4 & 5 & 6 & 7 & 8 & 9 & \text { P }\end{array}$

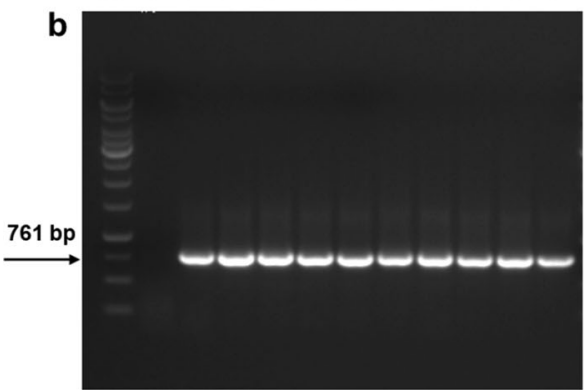

Figure 9 PCR analysis of genomic DNA from three different transgenic Theobroma cacao L. cv. INIAPG-038 events. Genomic DNA was extracted from leaf tissues of one non-transgenic control and three plants of each independent transgenic event. $M$, GeneRuler 1-kb DNA ladder; $C$, non-transgenic INIAPG-038 control; Lanes 1-3, transgenic INIAPG-038 event \#1-1, \#1-2, and \#1-3; Lanes 4-6, transgenic INIAPG-038 event \#21, \#2-2, and \#2-3; Lanes 7-9, transgenic INIAPG-038 event \#3-1, \#3-2, and \#3-3; $P$, pDDNPTYFP-2 as a positive control. (a) Amplified 595-bp

was the cause for all four genes being detected. The Agrobacterium strains containing the eyfp gene cassette showed no YFP expression and the YFP expression of the leaf samples of the third event was uniform and consistent with that of the other two events (Fig. S1). Stronger YFP expression driven by the CaMV35S promoter was observed in the leaf tissues compared to that driven by Nos promoter/TMV $\Omega$ enhancer. The presence of the Agrobacterium vector backbone sequences would then indicate that the third event was a readthrough event and those genes are additionally present with the other transgenes. Read-through is integration into the plant genome of complete vector backbone sequences which could be the result of a conjugative transfer initiated at the right border and subsequent continued copying at the left and right borders (De Buck et al. 2000). The ratio of the read-through plants in transgenic events ranges typically between 20 and $50 \%$ and is sometimes as high as $75 \%$ or more (De Buck et al. 2000; Wu et al. 2006; Komori et al. 2007; Cho et al. 2014)

In conclusion, we have established a successful Agrobacterium-mediated transformation system for the production of transgenic Theobroma cacao plants using INIAPG-038, a high-yielding, disease-resistant cultivar. Previously, only PSU SCA-6 has been reported for stable transformation. The results in this study can be applied to fragment products using enhanced yellow fluorescent protein (eyfp) genespecific primers, EYFP 3 F and EYFP 4R. (b) Amplified 761-bp fragment products using neomycin phosphotransferase II (nptII) gene-specific primers, NPTII 3F and NPTII 4R. (c) Amplified 562-bp fragment products using pVS1 replicon-specific primers, PVS1 1F and PVS1 2R. (d) Amplified 672-bp fragment products using neomycin phosphotransferase I (npt1) gene-specific primers, NPT1 1F and NPT1 2R.

improve tissue culture response and transformation frequency in other Theobroma cacao cultivars.

Supplementary Information The online version contains supplementary material available at https://doi.org/10.1007/s11627-021-10205-0.

Acknowledgements We are grateful to Alexandra Tempeleu and Brian Margolesky (Mars Cacao Laboratory, Miami, FL) for kindly shipping Theobroma cacao flowers.

Author contribution JJ and M-JC designed the experiments. DD and MG constructed vectors, and JJ, EZ, DT, and DR performed the experiments. BS and M-JC supervised the experiments. JJ, EZ, DT, and M-JC contributed towards writing the manuscript. CG, J-PM, DL, and RS provided protocol information, technical training, and donor materials. All authors read and approved the manuscript.

Funding This work was supported by Mars, Incorporated, and IGI, University of California at Berkeley.

\section{Declarations}

Ethics approval Research article followed the ethical standard of the institute.

Conflict of interest The authors declare no competing interests. 
Open Access This article is licensed under a Creative Commons Attribution 4.0 International License, which permits use, sharing, adaptation, distribution and reproduction in any medium or format, as long as you give appropriate credit to the original author(s) and the source, provide a link to the Creative Commons licence, and indicate if changes were made. The images or other third party material in this article are included in the article's Creative Commons licence, unless indicated otherwise in a credit line to the material. If material is not included in the article's Creative Commons licence and your intended use is not permitted by statutory regulation or exceeds the permitted use, you will need to obtain permission directly from the copyright holder. To view a copy of this licence, visit http://creativecommons.org/licenses/by/4.0/.

\section{References}

Bakhsh A, Anayol E, Ozcan S (2014) Comparison of transformation efficiency of five Agrobacterium Tumefaciens strains in Nicotiana Tabacum L. Emir J Food Agr 26:259-264. https://doi.org/10.9755/ ejfa.v26i3.16437

Belide S, Hac L, Singh SP, Green AG, Wood CC (2011) Agrobacteriummediated transformation of safflower and the efficient recovery of transgenic plants via grafting. Plant Methods 7:12. https://doi.org/ 10.1186/1746-4811-7-12

Bezdicek DF, Magee BH, Schillinger JA (1972) Improved reciprocal grafting technique for soybeans (Glycine max L.). Agron J 64:558. https://doi.org/10.2134/agronj1972.00021962006400040045x

Chetty VJ, Ceballos N, Garcia D, Narváez-Vásquez J, Lopez W, OrozcoCárdenas ML (2013) Evaluation of four Agrobacterium tumefaciens strains for the genetic transformation of tomato (Solanum lycopersicum L.) cultivar Micro-Tom. Plant Cell Rep 32:239-247. https://doi.org/10.1007/s00299-012-1358-1

Cho M-J, Jiang W, Lemaux PG (1998) Transformation of recalcitrant barley cultivars through improvement of regenerability and decreased albinism. Plant Sci 138:229-244. https://doi.org/10.1016/ S0168-9452(98)00162-9

Cho M-J, Jiang W, Lemaux PG (1999) High-frequency transformation of oat via microprojectile bombardment of seed-derived highly regenerative cultures. Plant Sci 148:9-17. https://doi.org/10.1016/S01689452(99)00082-5

Cho M-J, Wu E, Kwan J, Yu M, Banh J, Linn W, Anand A, Li Z, TeRonde S, Register JC III, Jones TJ, Zhao Z-Y (2014) Agrobacterium-mediated high-frequency transformation of an elite commercial maize (Zea mays L.) inbred line. Plant Cell Rep 33: 1767-1777. https://doi.org/10.1007/s00299-014-1656-x

Costa GGL, Cabrera OG, Tiburcio RA, Medrano FJ, Carazzolle MF, Thomazella DPT, Schuster SC, Carlson JE, Guiltinan MJ, Bailey BA, Mieczkowski P, Pereira GAG, Meinhardt LW (2012) The mitochondrial genome of Moniliophthora roreri, the frosty pod rot pathogen of cacao. Fungal Biol 116:551-562. https://doi.org/10. 1016/j.funbio.2012.01.008

da Silva TÉR, Cidade LC, Alvim FC, Cascardo JCDM, Costa MGC (2008) Somatic embryogenesis and plant regeneration in elite clones of Theobroma cacao. Pesq Agropec Bras 43:1433-1436. https://doi. org/10.1590/S0100-204X2008001000024

Dahleen LS (1995) Improved plant regeneration from barley callus cultures by increased copper levels. Plant Cell Tiss Org Cult 43:267269

De Buck S, de Wilde C, van Montagu M, Depicker A (2000) T-DNA vector backbone sequences are frequently integrated into the genome of transgenic plants obtained by Agrobacterium-mediated transformation. Mol Breed 6:459-468. https://doi.org/10.1023/A: 1026575524345

Esan EB (1975) Tissue culture studies on cocoa (Theobroma cacao L.) A supplementation of current research. In: Proceedings, Fifth
International Conference on Cacao Research Ibadan, Nigeria, pp $116-125$

Fister AS, Landherr L, Maximova SN, Guiltinan ML (2018a) Transient expression of CRISPR/Cas9 machinery targeting TcNPR 3 enhances defense response in Theobroma cacao. Plant Sci 9:268. https://doi. org/10.3389/fpls.2018.00268

Fister AS, Landherr L, Perryman M, Zhang Y, Guiltinan MJ, Maximova SN (2018b) Glucocorticoid receptor-regulated TcLEC2 expression triggers somatic embryogenesis in Theobroma cacao leaf tissue. PLoS One 13:e0207666

Florez SL, Erwin RL, Maximova SN, Guiltinan MJ, Curtis WR (2015) Enhanced somatic embryogenesis in Theobroma cacao using the homologous BABY BOOM transcription factor. BMC Plant Biol 15:121. https://doi.org/10.1186/s12870-015-0479-4

Garcia C, Corrêa F, Findley S, Almeida AA, Costa M, Motamayor JC, Ray S, Marelli JP (2016) Optimization of somatic embryogenesis procedure for commercial clones of Theobroma cacao L. Afr J Biotechnol 15:1936-1951. https://doi.org/10.5897/AJB2016.15513

Gotsch N (1997) Cocoa biotechnology: Status, constraints and future prospects. Biotechnol Adv 15:333-352. https://doi.org/10.1016/ S0734-9750(97)00008-6

Jin S, Liang S, Zhang X, Nie Y, Guo X (2006) An efficient system for transgenic plant recovery in cotton (Gossypium hirsutum L). Plant Cell Tiss Org Cult 85:181-186. https://doi.org/10.1007/s11240005-9068-9

Komori T, Imayama T, Kato N, Ishida Y, Ueki J, Komari T (2007) Current status of binary vectors and superbinary vectors. Plant Physiol 145:1155-1160. https://doi.org/10.1104/pp.107.105734

Li Z, Traore A, Maximova SN, Guiltinan MJ (1998) Somatic embryogenesis and plant regeneration from floral explants of cacao (Theobroma cacao L.) using thidiazuron. In Vitro Cell Dev Biol Plant 34:293-299. https://doi.org/10.1007/BF02822737

Lloyd G, McCown BH (1981) Commercially-feasible micropropagation of Mountain Laurel, Kalmia latifolia, by shoot tip culture. Proc Int Plant Prop Soc 30:421-427

Marelli JP, Guest DI, Bailey BA, Evans HC, Brown JK, Junaid M, Barreto RW, Lisboa DO, Puig AS (2019) Chocolate under threat from old and new cacao diseases. Phytopathology 09:1331-1343. https://doi.org/10.1094/PHYTO-12-18-0477-RVW

Maximova SN, Alemanno L, Young A, Ferriere N, Traoré A, Guiltinan MJ (2002) Efficiency, genotypic variability, and cellular origin of primary and secondary somatic embryogenesis of Theobroma cacao L. In Vitro Cell Dev Biol - Plant 38:252-259. https://doi.org/10. 1079/IVP2001257

Maximova SN, Marelli JP, Young A, Pishak S, Verica JA, Guiltinan MJ (2006) Over-expression of a cacao class I chitinase gene in Theobroma cacao L. enhances resistance against the pathogen, Colletotrichum gloeosporioides. Planta 224:740-749. https://doi. org/10.1007/s00425-005-0188-6

Maximova SN, Miller C, De Mayolo GA, Pishak S, Young A, Guiltinan MJ (2003) Stable transformation of Theobroma cacao L. and influence of matrix attachment regions on GFP expression. Plant Cell Rep 21:872-883. https://doi.org/10.1007/s00299-003-0596-7

Meinhardt LW, Costa GGL, Thomazella DPT, Teixeira PJPL, Carazzolle MF, Schuster SC, Carlson JE, Guiltinan MJ, Mieczkowski P, Farmer A, Ramaraj T, Crozier J, Davis RE, Shao J, Melnick RL, Pereira GAG, Bailey BA (2014) Genome and secretome analysis of the hemibiotrophic fungal pathogen, Moniliophthora roreri, which causes frosty pod rot disease of cacao: mechanisms of the biotrophic and necrotrophic phases. BMC Genomics 15:164. https://doi.org/ 10.1186/1471-2164-15-164

Mejía LC, Guiltinan MJ, Shi Z, Landherr L, Maximova SN (2012) Expression of designed antimicrobial peptides in Theobroma cacao L. trees reduces leaf necrosis caused by Phytophthora spp. ACS Symposium Series, 1095 Chapter 18 pp 379-395 https://doi.org/ 10.1021/bk-2012-1095.ch018 
Mondego JMC, Carazzolle MF, Costa GGL, Formighieri EF, Parizzi LP, Rincones J, Cotomacci C, Carraro DM, Cunha AF, Carrer H, Vidal RO, Estrela RC, Garcia O, Thomazella DPT, de Oliveira BV, Pires ABL, Rio MCS, Araujo MRR, de Moraes MH, Castro LAB, Gramacho KP, Goncalves MS, Moura Neto JP, Goes Neto A, Barbosa LV, Guiltinan MJ, Bailey BA, Meinhardt LW, Cascardo JCM, Pereira GAG (2008) A genome survey of Moniliophthora perniciosa gives new insights into Witches' Broom Disease of cacao. BMC Genomics 9:548. https://doi.org/10.1186/1471-2164-9548

Murashige T, Skoog F (1962) A revised medium for rapid growth and bioassays with tobacco tissue cultures. Physiol Plant 15:473-497. https://doi.org/10.1111/j.1399-3054.1962.tb08052.x

Murray MG, Thompson WF (1980) Rapid isolation of high molecular weight plant DNA. Nuc Acid Res 8:4321-4325. https://doi.org/10. 1093/nar/8.19.4321

Pokou DN, Fister AS, Winters N, Tahi M, Klotioloma C, Sebastian A, Marden JH, Maximova SN, Guiltinan MJ (2019) Resistant and susceptible cacao genotypes exhibit defense gene polymorphism and unique early responses to Phytophthora megakarya inoculation. Plant Mol Biol 99:499-516. https://doi.org/10.1007/s11103-01900832-y

Shires ME, Florez SL, Lai TS, Curtis WR (2017) Inducible somatic embryogenesis in Theobroma cacao achieved using the DEXactivatable transcription factor-glucocorticoid receptor fusion.
Biotechnol Lett 39:1747-1755. https://doi.org/10.1007/s10529017-2404-4

Susilo AW, Mawardi S, Sudarsianto S (2009) Yield performance of cacao clones of SCA6 and DRC15 resistant to vascular-streak dieback. Pelita Perkebunan Coffee and Coca Res J 25:76-85. https://doi. org/10.22302/iccri.jur.pelitaperkebunan.v25i2.131

Tan CL, Furtek DB (2003) Development of an in vitro regeneration system for Theobroma cacao from mature tissues. Plant Sci 164: 407-412. https://doi.org/10.1016/S0168-9452(02)00428-4

Traore A, Guiltinan MJ (2006) Effects of carbon source and explant type on somatic embryogenesis of four cacao genotypes. HortScience 41: 753-758. https://doi.org/10.21273/HORTSCI.41.3.753

Wickramasuriya A, Dunwell JM (2018) Cacao biotechnology: current status and future prospects. Plant Biotechnol J 16:4-17. https://doi. org/10.1111/pbi. 12848

Wu H, Sparks CA, Jones HD (2006) Characterisation of T-DNA loci and vector backbone sequences in transgenic wheat produced by Agrobacterium-mediated transformation. Mol Breed 18:195-208. https://doi.org/10.1007/s11032-006-9027-0

Zhang D, Gardini EA, Motilal LA, Baligar V, Bailey B, Zuñiga-Cernades L, Arevalo-Arevalo CE, Meinhardt L (2011) Dissecting genetic structure in farmer selections of Theobroma Cacao in the Peruvian Amazon: implications for on farm conservation and rehabilitation. Trop Plant Biol 4:106-116. https://doi.org/10.1007/s12042-0109064-Z 